\title{
Imagem \\ Ondas T Anômalas em Bloqueio Completo de Ramo Esquerdo, na Cardiomiopatia não Compactada do Ventrículo Esquerdo
}

\author{
Anomalous T Waves in the Complete Left Bundle Branch Block in the Non- \\ Compaction Cardiomyopathy of the Left Ventricle
}

\author{
Lurildo R. Saraiva, Ricardo Loureiro, Djair Brindeiro Filho \\ Recife, PE
}

Operário de 29 anos compareceu ao Serviço de Cardiologia da UFPE, referindo dispnéia progressiva e precordialgia atípica ("furada"), iniciadas há dois meses. Manuseava lixo de restaurante e, periodicamente, fazia abuso de álcool.

Com pressão arterial de $130 \times 90 \mathrm{mmHg}$, tinha ritmo cardíaco regular, auscultando-se o componente mitral da 10 bulha abafado e intensa $4 \stackrel{\circ}{\circ}$ bulha. Havia hepatomegalia, com dor à palpação da víscera, e não eram observados estigmas de doença hepática crônica.

0 eletrocardiograma (fig. 1) revelou sobrecarga do ventrículo esquerdo e bloqueio completo do ramo esquerdo, com ondas $T$ bífidas em D1, do "tipo infantil" em V4 e minus-plus em V5 e V6. O QTm correspondia a 0,440s. O ecoDopplercardiograma demonstrou hipertrofia excêntrica do ventrículo esquerdo, com diâmetro diastólico de $6,0 \mathrm{~cm}$, hipocinesia e disfunção diastólica tipo II dessa câmara, assincronia do septo e fração de ejeção de 0,43 . A angioressonância magnética (fig. 2) foi compatível com ventrículo esquerdo não compactado.

Comentários - Descrita há poucos anos, a não compactação do ventrículo esquerdo comparece em Clínica em proporção crescente. Embora o ecoDopplercardiograma seja aceito como de eleição no diagnóstico ${ }^{1}$, a ressonância magnética pode ser de maior relevo. Cardiomiopatia dilatada distinta, de maior prevalência em meninos, grupo em que pode estar associada a outras anomalias congênitas, é vista isoladamente também no adulto, onde são queixas habituais, a diminuição da tolerância ao esforço, palpitações e mal estar precordial, com 4 ำ ruído sempre presente no exame físico ${ }^{1}$, como neste caso.

Há múltiplas alterações no eletrocardiograma, mas o bloqueio completo do ramo esquerdo é detectado em enfermos adultos em torno de $44 \%$ das vezes, sendo um dos indicadores de mau prognóstico ${ }^{1}$. A peculiariedade da repolarização ventricular, com a presença de ondas $T$ anômalas, do tipo infantil, em derivações esquerdas, pode ser um achado valioso no seu diagnóstico (Moffa PJ , comunicação pessoal, 2004), possivelmente, de maior significado, quando simultâneas ao distúrbio de condução, como se decorressem de rotação horária no plano horizontal.

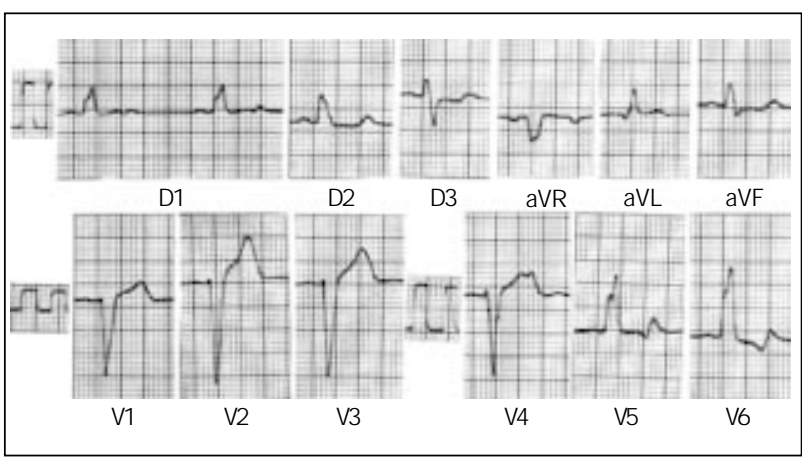

Fig. 1 - Bloqueio completo de ramo esquerdo, observando-se ondas T bífidas em D1, do tipo infantil em V4 e minus-plus em V5 e V6.

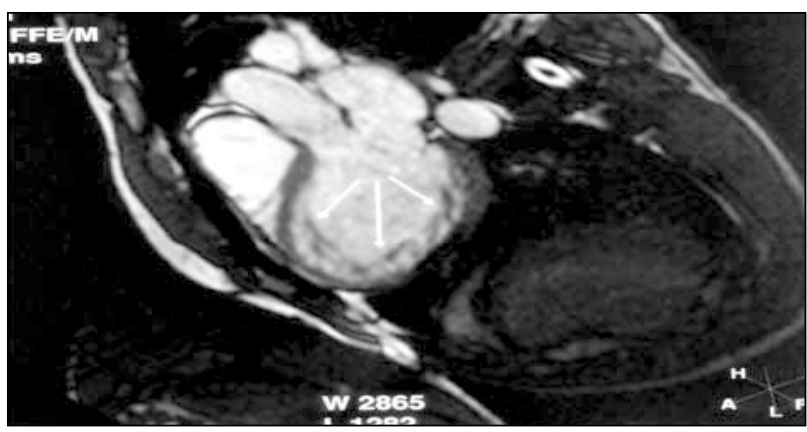

Fig. 2 - Ventrículo esquerdo de dimensões aumentadas, com padrão de imagem em dupla camada (interna não compactada, externa compactada), por trabeculação endomiocárdica excessiva e recessos intertrabeculares profundos, na regiões médio-apical, inferior e lateral (setas).

\section{Referência}

1. Weiford BC, Subbarao VD, Mulhern KM. Noncompaction of the ventricular myocardium. Circulation 2004;109:2965-71.

Disciplina de Cardiologia - Hospital das Clínicas UFPE

Endereço para correspondência - Dr. Lurildo R. Saraiva - Disciplina de Cardiologia - Hospital das Clínicas UFPE - Av. Prof. Moraes Rego, SN - Cidade Universitária - Cep 52070-420 - Recife - PE

E-mail: lurildocleano@ hotmail.com 